\title{
Digital Technology: An Influential Factor in Investment Decision Making
}

\author{
S. Solanki, S. Wadhwa, S. Gupta
}

\begin{abstract}
The purpose of this study is to present a conceptual framework for thinking about the role of digital technology and highlights the factors which influence the investors to make the investment decision. Researchers examined the change found in the behavior of individual investors before and after digitalization. Researchers have also identified the various benefits which an investor derives from the use of digital technology as it's an open platform to compare available investment solutions, possibility of easy comparison of return, internet posting to choose investment related options, self decision to make investment without human involvement which showcase the influence of the information (available through internet via websites application) on the behavior of an individual investor i.e. how does he react to particular information received (e.g. what impact internet posting have on the decision of an investor). In addition to this, the use of digital technology has also changed the way of presenting a piece of information to the investors to reach at investment conclusion.
\end{abstract}

Keywords: Digital technology, Investors, Investment Decision, Digitalization.

\section{INTRODUCTION}

The use of digital technology is rapidly increasing and the major factor contributing to this digital technology is Internet. The Internet is changing how information is delivered to investors and the ways in which investors can act on that information and the technological developments associated with the Internet are likely to affect the performance of investors and financial markets. (Barber \& Odean, 2001). The versatility of internet services supported by widespread digital technology appeals to investors. Overall, investors appreciate and want technology to be the part of their lives. Almost 9 out of 10 say that technology makes some of their favorite activities possible (86\%) and the same number says that if technology can make their lives easier, they want it $(86 \%)$. Further, 3 in 4 say they are excited to try new technologies $(74 \%)$, and half consider themselves early adopters (48\%). Investors already see the value and benefits of the hybrid model, combining human expertise with machine learning and artificial intelligence. They believe that technology will help provide the simplicity they desire, and the analysis they need, and help them to optimize their returns. In this Digital 2.0 era, contextual factors such as Internet and Technology should be examined in order to

determine the likelihood of investors for making decision of Investments.Web 2.0 has enabled the creation of websites and application by anyone who wants to share information online.

Revised Manuscript Received on November 25, 2019.

*Corresponding author

S. Solanki, Assistant Professor, School of Management, Graphic Era Hill University, Dehradun, Uttarakhand, India.

S. Wadhwa* Assistant Professor, School of Management, Graphic Era Hill University, Dehradun, Uttarakhand, India.

S. Gupta, Associate Professor, School of Commerce, Graphic Era Hill University, Dehradun, Uttarakhand, India.
Technology has advanced to an extent that sometimes it becomes difficult to understand how a particular technology works. It has been found that many times people unconsciously relate technology with the notion of success and on the basis of this make their investment decision.

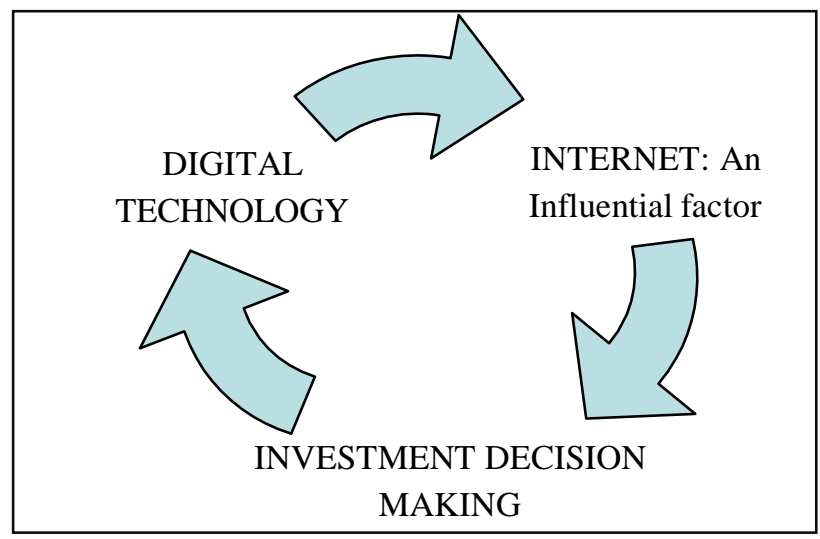

The behavior of investors varies after the digitalization. It is evident from previous literature that individual investors are likely to get influenced from the information they derive from different sources available online. Before making an investment decision an investor has plenty of information which must be filtered as to what is qualitative for them and what is not, for a particular investment decision. Information overload results in overestimation in the accuracy of the knowledge and judgment which in turns results in the form of increased investment and decline in investment performance. In addition to this with excessive information the ability to predict declines. Technology has also made the society connect online through various social platforms. It is being observed that an investment decision of individuals is being influenced by several internet postings. Social platform like facebook and twitter are being used by companies to display its performance so as to attract investors. Although it also shows that companies are bias towards displaying favourable performance on the social platform. Other than the companies those who post online comments are regarded as the sophisticated investors who influence the trading behavior of others. It has been outlined earlier that the traders who post comments online reflect the information which relates to their recent successful performance. The individuals following them are regarded as unsophisticated investors, who follow the successful transaction of the traders and the resultant effect of which is worst investment performance(Followers).Though it has been observed that the online post do not predict the future performance, still the followers replicate the transaction, which shows their sentimental bias. Individuals need a platform where they could get access to information at a lower cost which is significant to their investment decision and help recommend them the best option that would help them earn better future

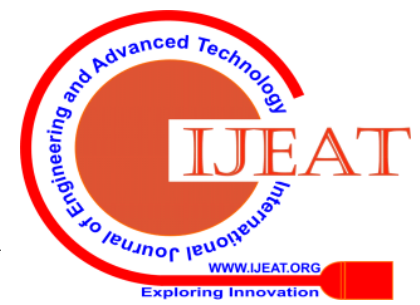


returns. A Decision support system bulid with the expert opinion can help investors get their queries being handled at a single platform with an add on feature of recommendation that would help in building an appropriate portfolio. With different expert opinion the platform is inculcated with diversity of information giving multiple options according to individual criteria. A direction in this context supports the investment decision making process in a better way.

\section{CONCEPTUAL ASPECTS OF DIGITAL TECHNOLOGY AND INVESTMENT DECISION MAKING:}

Internet as a component of technology has provided the information that would otherwise have gone unexplored. There was a time when individual had to spend many hours to consult an expert with several years of experience to take investment decision which can now be done with an automated algorithm in span of seconds. The investors today have alternatives that were unprecedented ten years ago. The environment has now become challenging for the traditional practices as human activities in the form of services provided by people have been replaced by services provided by the software and computers. With the use of Internet there is an access to ample amount of information, making it convenient for the investors to trade at a reduced cost. Perhaps the website will help investor know the new methods of quicker trading at reduced cost (Barber\& Odean, 2001).

Past studies have shown that when people are explored to abundant information, their confidence level in the precision to forecast increases very fast than the precision of that forecast. (Oskamp, 1965; Hoge, 1970; Slovic, 1973; Peterson and Pitz, 1988). It is evident that internet has made trading convenient for investors in terms of reduced cost (Walia \& Kumar, 2007). The use of technology has reduced the time consumption of Investors and makes their life more convenient by providing several benefits like prediction for future and control over their accounts. Research shows that at a certain point, with more and more information the ability to predict also declines. (Stewart, Heideman, Moniger and Reagan- Cirincione, 1992; Keller and Staelin, 1987).

According to Mirsch, T. et al., (2017), Investors due to extensive information available on internet are not able to reach at desirable conclusion as they are unable to process complete information which is significant. Individuals tend to make decision in a speedy manner on screens. Excessive information through Internet leads to illusion of knowledge which makes an individual overconfident in his ability to select stock. (Barber and Odean, 2000b; Barber and Odean, 2001). Overconfidence bias results in judgmental errors which an investors commit while taking an investment decision. Investors overestimate their skills in terms of knowledge, analyzing the investment options and become ignorant to the risk involves which ultimately leads to improper construction of portfolio (Pompian, M. M, 2006).

Yang et al. (2017) on the basis of a small survey analyzed the impact of mass media, social media on investor's investment decision. It is evident that with market fluctuation investors react differently to media reports. When the market upturns, the investors are likely to pay attention to promising reports, and avoid reports with

negative consequences. The reaction is indifferent, when the market takes a downturn; the investors are more likely to attract pessimistic reports. Moreover companies communicate firm's performance and other related information using social media as a platform (Zhou et al., 2014).

Siikanena et al., (2018) illustrated that sharing information through social platform such as facebook is likely to affect the trading behaviour of individuals. It can be clearly seen that unsophisticated investors specifically the households are likely to increase their investment after the exploration of facebook data. Internet posting in the form of comments results both way. At one end it motivates some new followers to act on the basis of that information and at the other end it encourages others to withdraw. The overall impact of internet posting is positive as there in an increase in investment by $12.9 \%$ while an increase in the number of investors who walk away is just $4.3 \%$. In total, our sample includes 43,676 transactions executed by followers into and out of trading strategies, of which 28,742 are investments and 14,932 are withdrawals. It distinguished the trading behavior of those who posted investment related comments online and also the trading behavior of those who go after following and sharing those posts. It is evident from the research that performance with beneficial consequences encourages investors to post online comments and also increase the proportion of positive words in their expression. This shows that posting comments online are biased towards beneficial outcomes. (Ammann \& Schaub, 2017). Investors are more inclined to showcase their favourable outcome via online posting and avoid broadcasting the failures (Han and Hirshleifer, 2016).

Jung et al., (2017) after examining the S\&P 1500 firms' quarterly announcement of earnings concluded that firms are less likely broadcasting an unfavourable information about their performance. In addition to it, tweeting an unfavourable information results in more negative words put down by the media which ultimately result in companies put forward more of positive outcomes on social media platform. In the past, researchers have reported that there is a significant relation between point of views shared on online platform and future yield. (e.g., Chen et al., 2014; Avery et al., 2016; Crawford et al., 2017). Others believe that there is no such forecasting relationship between the two (e.g., Tumarkin and Whitelaw, 2001; Dewally, 2003; Antweiler and Frank, 2004; Das and Chen, 2007).

Snow and Rasso (2017) cited evidence that company's performance communicated through social media is likely to exert more influence on unsophisticated investors as using this platform makes information easy to obtain. Ammann \& Schaub (2017) further added in the earlier research studies that even if the internet post are evident to be less valuable still investors depend on information posted online. It is found that the comments posted online by the sophisticated investors are much more influential than those who are less sophisticated. As a result of which performance of traders decline. The traders who follow and share the comments mostly are the small investors regarded as the less skilled participants of market. It has been observed that internet posting urge followers to imitate the successful transactions of traders so that they reap benefits from it. 
But ultimately an investment decision taken under such an influence would result in poor performance of investment. The study examines the role of emotional bias as a driving force behind their reactions to such posts and not the rationality in it. Previous literature suggested that sophistication has been found in large traders, the investors who are wealthy and better informed as compared to small traders, the investors who are less wealthy and less informed Snow and Rasso (2017). It has been found that Investors are looking for a customized platform, which will help them to solve their investment related issues. They also look forward to the emerging technology such as artificial intelligence and machine learning for financial management. In this perspective, Decision support system can be supportive technique for meeting the requirements of Investors. Decision Support system (DSS) is a combination of massive amount of data source, expert aid, calculation methods that helps in providing the multiple options that ultimately helps to solve a given problem. (Druzdzel, Flynn., 1999). The major challenge posed by DSS is procuring of accurate data which in itself is a difficult, expensive and time consuming. (Er 1988; Geurts 1994).

It becomes difficult to make a choice when it comes to investment decision, due to variety of alternatives available. This difficulty is faced both by individual investor and portfolio managers, as the investment decision is in itself very complicated and surrounded by the risk of sudden possible losses. In this relation Decision support system (DSS) is appearing as a significant structure that assist the process of investment decision. Weber, B.W. (2008) highlighted the importance of DSS as a significant tool that help investors take better investment decision even when exposed to ample amount of investment choices and wide variety of market data. A financial DSS will guide an individual in optimum allocation of their financial resources and also providing the investment institutions possible methods that would help in managing the pool of resources in a better way. As Individuals are exposed to market situations encircled by price variation and uncertainity, their decision is bound to get influenced by cognitive biases which results in poor quality decision (Dawes 1988).

A DSS need to develop gradually with time the reason being the change in requirement, technology advancement. In this context, Courbon et al. (1978) is considered as a pioneer for using the concept of evolution in DSS in their study .However, Lehman (1998) underlined DSS software modification and upgradation as a never ending process. This states that with identification of different problems faced by individual's overtime, a DSS can be modified to serve them with better information. A DSS designer must take into consideration the evolving situations and dynamic environment when designing a DSS so that multiple portfolio options are available that would support decision making. It is evident that DSS results in reduction in Bias that is caused due to the individual cognitive and emotional process. The knowledge base of the DSS must be immensely large to gain trust and in addition to this the content should be useful and up to date. (Assuli, O.B., 2012).

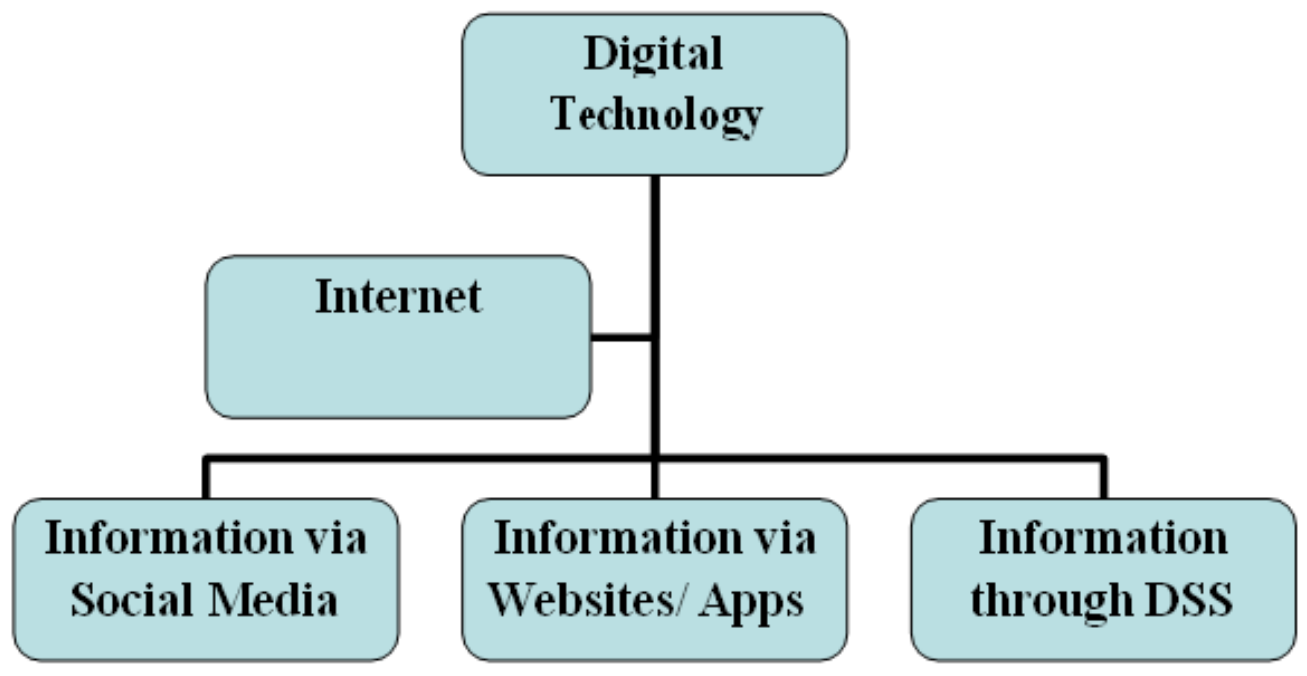


III. CONCEPTUAL FRAMEWORK

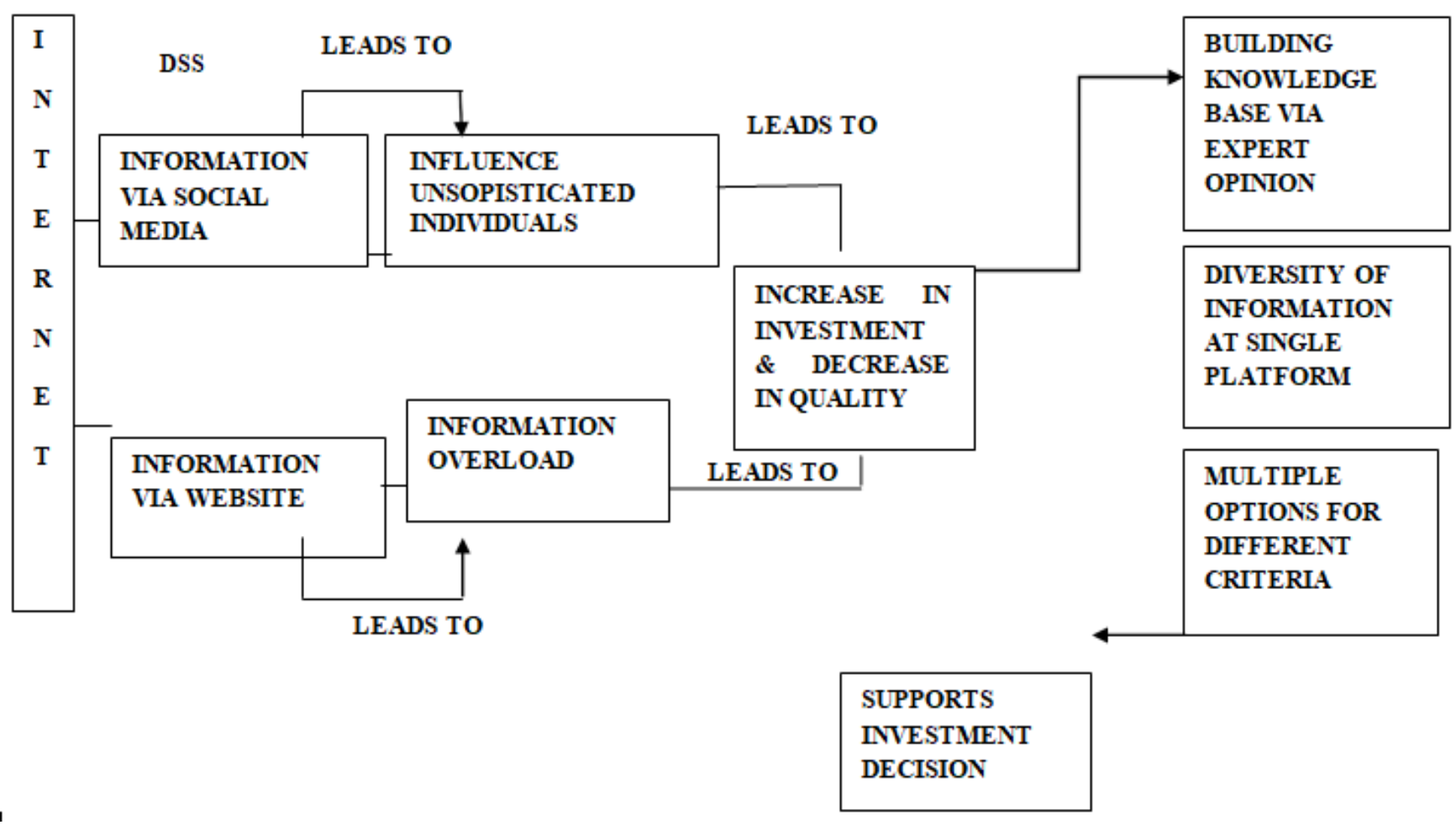

\section{Discussion and Findings}

Predicting the future performance of an investment necessitate rational thinking and relevant information. Internet has overcome the limitation of lack of information and has furnished us with a platform where we can gain access to a vast amount data in relation to an investment.It is evident that in addition to the easy access to information at least cost, internet as a component of technology has made trading easier (Walia \& Kumar, 2007). There are many information sources available online i.e websites, applications, social media platform .Though with extensive information it convenient for an investor to make comparison between various investment options, at the same time it is argued that with excessive information the ability to predict declines. If an investor is not able draw a demarcation between the useful and purposeless information for a particular decision, then they are vicious circle of information overload. Barber and Odean, (2000b); Barber and Odean, (2001) argued that excessive information leads to overconfidence in the ability to select a stock which is the resultant effect of illusion of knowledge which means overestimation of one's ability as correct. Social media is a trending platform affecting the way people make investment choices. The influence of internet posting has found to be positive .The impact of internet posting can be observed in the form of increased investment. Moreover it is the favorable information that is being posted online by a company or individual trader on social platform such as facebook or twitter which showcase their biaseness towards favourable outcomes.

Though the information found on these platform have proved to be of less value, still the less skilled (small trader) individuals follow these internet posting to make an investment decision.and end up earning low or no returns unsophisticated traders. The traders usually influencing the trading behavior of individuals are classified as This draws a distinction between the sophisticated and

sophisticated while the traders who follow and share the comments mostly are the small investors regarded as the less skilled participants of market(unsophisticated traders) (Ammann \& Schaub (2017).

Investors require a more refined platform where their key issues related to investment are addressed. Though there are platform available to address such issues separately, but there is a need for a more comprehensive structure that would act as single platform catering to all investment related issues and also recommending a constructive portfolio.With this the significance of DSS is realized. Just as a DSS helps organizations reach an optimal conclusion. A DSS structure created with experts help in establishing a single online platform with diversity of information catering to various issues, making recommendation, help managing the portfolio. As Individuals are exposed to market situations encircled by price variation and uncertainity, their decision is bound to get influenced by cognitive biases which results in poor quality decision (Dawes 1988). It is evident that DSS results in reduction in Bias that is caused due to the individual cognitive and emotional process (Assuli, O.B., 2012).

\section{CONCLUSION}

The development in the technology results in expectations of investors which further helps in improving their investing performance and experience. They see the benefits of these technologies in their everyday life, and are eager to adopt them in their financial lives. In our study we lay stress on the key issues which an investor face while making judgment on the basis of the information they retrieve from the online platform such as information through website and social media. 
Such issues are mainly faced by the unsophisticated investors who are not skilled enough to demarcate between useful and useless information related to their investment. This is the reason that they are more active in their reaction when explored to excessive information either through website information, applications, or social platforms such as facebook, twitter etc.There is a need to address their issues and providing them with a single online platform that is equipped with the information which is relevant to their investment, making recommendation, and managing their portfolio. A DSS build with the expert advice containing diverse information will help to address all investment related query at one platform and helps in providing immediate solution.

\section{FUTURE SCOPE OF STUDY}

The study may not prove a success in all investment decision and focus significantly on the investors trading in the secondary market, and cater to their investment related issues. The study itself is based on the finding of already existing literature on the basis of which conclusions have been drawn. Digital technology encompasses various components but this research study is limited to internet information via social media and websites as an influencial factor in investment decision. Furthermore, the study has identified DSS as a single platform to help in reaching the investment decision which can further be analyzed in future by recording the respondents through empirical results and helps in validating the current study.

\section{REFERENCES}

1. Antweiler, W., and M.Z. Frank, (2004) Is all that talk just noise? The information content of Internet stock message boards, Journal of Finance,59, 1259-1294.

2. Ammann, M., Schaub, N., (2017) The impact of internet postings on individual investors. In: proceedings American Finance Association 2018 Annual Meeting.

3. Assuli,O.B., (2012) Assessing the perception of information components in financial decision support system, Decision support system, 54, 795-802.

4. Avery, C.N., J.A. Chevalier, and R.J. Zeckhauser, (2016) The "CAPS" prediction system and stock market returns, Review of Finance, 20, 1363-1381.

5. Barber, M.B ,\& Odean, T.(2001). The Internet and the Investor, Journal of Economic Perspective. 15, pp. 41-54.

6. Barber, Brad M. and Terrance Odean. (2001) "Boys Will be Boys: Gender, Overconfidence, and Common Stock Investment,' forthcoming Quarterly Journal of Economics.

7. Chen, H., D. Prabuddha, Y.J. Hu, and B.-H. Hwang, (2014) Wisdom of crowds: The value of stock opinions transmitted through social media, Review of Financial Studies, 27, 1367-1403.

8. Crawford, S.S., R.G. Wesley, and A.E. Kern, (2017) Why do fund managers identify and share profitable ideas?, Journal of Financial and Quantitative Analysis, forthcoming.

9. Courbon, J.C., J. Grajew and J. Tolovi, (1978) "Design and Implementation of Interactive

10. Decision Support Systems: An Evolutionary Approach,' Technical Report, Institute

11. d'Administration des Enterprises, Grenoble, France.

12. Das, S.R., and M.Y. Chen, (2007) Yahoo! for Amazon: Sentiment extraction from small talk 26 on the web, Management Science 53 1375-1388.

13. Dawes, R.M., Rational Choice in an Uncertain World. Harcourt, 1988.

14. Dewally,M.,(2003) Internetinvestmentadvice: Investing with a rock of salt, Financial Analyst Journal, 59, 65-77

15. Druzdzel, M.J. \& Flynn, R.R., (1999) Decision support systems. Encyclopedia of library and information science, Marcel Dekker, Inc. Last Login.

16. Er, M.C., (1988) Decision Support Systems: A Summary, Problems, and Future Trends, Decis. Support Syst., 4(3), pp. 355-63.
17. Geurts, M.D., (1994) Data problems in decision support systems. Hawaii International Conference on System Sciences, IEEE, pp. 1558.

18. Han, B., and D. Hirshleifer, (2016) Social transmission bias and active investing, Working Paper, Rotman School of Management.

19. Hoge, Robert D. (1970) "Confidence in Decision as an Index of Perceived Accuracy of Information Processing." Psychonomic Science. 18, pp. 351-53.

20. Jung, M. J., Naughton, J. P., Tahoun, A., Wang, C., (2017) Do firms strategically disseminate? evidence from corporate use of social media. Forthcoming in the Accounting Review.

21. Keller, Kevin L. and Richard Staelin (1987) "Effects of Quality and Quantity of Information on Decision Effectiveness." Journal of Consumer Research. 14, pp. 200-13.

22. Lehman, M.M., (1998) "Software's Future," IEEE Software, 40-44.

23. Mirsch, T.; Lehrer, C.; Jung, R. (2017): Digital Nudging: Altering User Behavior in Digital Environments, in Leimeister, J.M.; Brenner, W. (Hrsg.): Proceedings der 13. International en Tagung Wirtschaftsinformatik (WI 2017), St. Gallen, S. 634-648

24. Oskamp, Stuart. (1965) "Overconfidence in Case-study Judgments." Journal of Consulting Psychology. 29, pp. 261-65

25. Peterson, Dane K. and Gordon F. Pitz. (1988) "Confidence, Uncertainty, and the Use of Information." Journal of Experimental Psychology. 14, pp. 85-92.

26. Pompian, M. M. (2006). Behavioral Finance and Wealth Management. John Wiley \& Sons Inc.

27. New Jersey.

28. Snow, N. M., Rasso, J., (2017) If the tweet fits: How investors process financial information received via social media. SSRN working paper

29. Slovic, Paul.(1973) "Behavioral Problems of Adhering to a Decision Policy," Working paper, Oregon Research Institute, Eugene, Oregon.

30. Siikanena,M., Baltakysa,B., Kanniainena,J., Vatrapub, R., Mukkamalab,R., Hussainb,A., (2018) Facebook Drives behavior of Passive household in Stock Market. Finance Research Letters, 27,208-213

31. Stewart, Thomas R., Kenneth F. Heideman, William R. Moninger and Patricia Reagan- Cirincione. (1992) "Effects of Improved Information on the Components of Skillin Weather Forecasting." Organizational Behavior \& Human Decision Processes. 53, pp. 107-34.

32. Tumarkin, R., and R.F. Whitelaw, (2001) News or noise? Internet postings and stock prices,

33. Financial Analyst Journal, 57, 41-51.

34. Walia Nidhi and Ravinder Kumar (2007), "Online Stock Trading in India: An Empirical Investigation”, Indian Journal of Marketing, 4, pp.42-49

35. Weber, B. W (2008) Financial DSS: Systems for Supporting Investment Decisions.

36. Handbook on Decision Support Systems 2, pp. 419-442

37. Yang, W., Lin, D., Yi, Z., (2017) Impacts of the mass media effect on investor sentiment.

38. Finance Research Letters, 22, 1-4.

39. Zhou, M., Lei, L., Wang, J., Fan, W., Wang, A. G., (2014) Social media adoption and corporate disclosure. Journal of Information Systems, 29 (2), 23-50. 